\title{
Moldagem com casquete: uma variação na técnica
}

\section{Shell tray impression: a technique modification}

\begin{abstract}
Wilson Matsumoto', Rossana Pereira de Almeida Antunes², Regina Maura Fernandes ${ }^{3}$, lara Augusta Orsi ${ }^{4}$, Takami Hirono Hotta ${ }^{5}$

'Doutor em Reabilitação Oral. Docente na Universidade de São Paulo. Ribeirão Preto, São Paulo, Brasil.wmatsumoto@forp.usp.br ${ }^{2}$ Doutora em Reabilitação Oral. Docente na Universidade de São Paulo. Ribeirão Preto, São Paulo, Brasil. rpaa@forp.usp.br ${ }^{3}$ Doutora em Reabilitação Oral. Docente na Universidade de São Paulo. Ribeirão Preto, São Paulo, Brasil. refernandes@forp.usp.br

${ }^{4}$ Doutora em Reabilitação Oral. Docente na Universidade de São Paulo. Ribeirão Preto, São Paulo, Brasil. iaraorsi@forp.usp.br ${ }^{5}$ Autora para correspondência. Doutora em Reabilitação Oral. Docente na Universidade de São Paulo. Ribeirão Preto, São Paulo, Brasil. takamihotta@forp.usp.br
\end{abstract}

Resumo | Introdução: A obtenção de um modelo de trabalho preciso em prótese parcial fixa é fundamental para se atingir o sucesso e está relacionada, principalmente, às técnicas e material de moldagem. Há várias técnicas para obtenção do modelo de trabalho e troquéis para confecção de prótese parcial fixa, dentre elas está a técnica do casquete. Objetivo: Este trabalho tem o objetivo de apresentar uma variação na técnica de reembasamento do casquete confeccionado previamente com resina acrílica convencional. Material e Métodos: Nesta técnica, o casquete é completamente preenchido com resina acrílica (Duralay) em uma única mistura, a qual é manuseada até a fase plástica e então, o conjunto casquete/resina duralay é inserido no dente preparado para copiar a linha de término do preparo. Resultados: A vantagem é que a fase plástica da resina acrílica possui baixa quantidade de monômero livre e adequada consistência para promover o afastamento gengival provocando desconforto mínimo ao paciente e possui adequada consistência para promover o afastamento gengival. Não é necessária a troquelização do modelo. Conclusão: Conclui-se que essa variação técnica tem aplicação clínica simples e eficaz e produz troquéis de gesso muito precisos.

Palavras-chave: Materiais para moldagem odontológica; prótese parcial fixa; técnica de moldagem odontológica

\begin{abstract}
Introduction: Obtaining an accurate working cast for a fixed partial denture is fundamental in achieving a successful restoration and is dependent on the impression materials and dental impression techniques. To fabricate a fixed partial denture, several impression techniques are used to obtain working casts or stone dies; one of them is the shell technique. Objective: The objective of the present study was to demonstrate a variation of the relining technique of the early-made acrylic resin shell. Methods and materials: In this technique, the shell was filled with a single mixture of acrylic resin (e.g., Duralay) that was manipulated until it reached a dough-like stage. The shell/ resin set was then placed on the prepared tooth to copy the finish lines. Results: During the dough-like stage, the acrylic resin had a low quantity of free monomers, provoked minimal discomfort for the patient, and had adequate consistency for promoting gingival retraction. Conclusion: The results showed that clinical application of this technical variation is simple and effective and produces a highly precise stone die.
\end{abstract}

Keywords: Dental impression materials; fixed partial denture; dental impression technique. 


\section{Introdução}

O sucesso de uma restauração protética depende, dentre outros fatores, da obtenção de modelos de trabalho precisos. Dessa maneira, entende-se que os materiais e as técnicas de moldagem são alguns dos fatores relevantes para o sucesso da reabilitação oral, fato comprovado pela quantidade de artigos científicos sobre o assunto'. Para realização da moldagem, é necessário criar um espaço entre o dente preparado e a área correspondente ao sulco gengival, por meio de afastamento da gengiva, para expor a região e permitir a inserção do material de moldagem que irá copiar o término cervical do preparo ${ }^{2}$.

Geralmente, na prática odontológica, a opção por uma técnica ou material de moldagem tem relação com a facilidade de execução do procedimento, com ○ fator custo/benefício/tempo dispendido e com o resultado final do produto obtido.

À técnica de moldagem com casquete são atribuídas vantagens como moldes com boa reprodução do preparo, reduzido trauma ao tecido gengival ${ }^{3}$, economia de material e tempo, facilidade de trabalho clínico'.

Esta técnica é realizada em 5 etapas: 1) confecção dos casquetes em resina utilizando o modelo de gesso ou as coroas provisórias 4 ou diretamente na boca do paciente sobre o dente preparado, 2) reembasamento dos casquete com resina acrílica (Duralay - Reliance Co - EUA), 3) Moldagem com elastômeros, 4) Remoção do molde e 5) Obtenção do modelo de trabalho.

Este trabalho tem o objetivo de apresentar uma variação na técnica de reembasamento de casquete $e$ propor a remoção isolada do mesmo, após moldagem com material de moldagem selecionado, visando obtenção direta do troquel de gesso.

\section{Metodologia}

\section{Obtenção direta do casquete}

Manipular a resina autopolimerizável (Jet Clássico - Brasil) em um pote de dappen com o auxílio de espátula ${ }^{7}$. Fazer um rolete com essa resina e adaptar sobre o dente preparado, previamente umedecido com água para evitar aderência da resina. $O$ formato deve envolver o dente preparado, seguindo seu longo eixo e possibilitar sua apreensão pelo operador. Retirar da boca do paciente e colocar em um recipiente com água para o término da polimerização da resina.

\section{Realização de desgastes externos e internos do casquete}

Com fresa de tungstênio de corte transversal realizar o desgaste externo do casquete eliminando os excessos, deixando as superfícies retas, exceto na face vestibular do casquete que terá uma depressão para identificar o lado vestibular do casquete e facilitar os procedimentos de ajuste e moldagem. Retornar o casquete sobre o dente preparado e verificar a adaptação inicial (Figura 1). Com a fresa de tungstênio, aliviar o interior do casquete, em profundidade pela inserção da fresa no sentido do longo eixo e em largura pela inclinação da mesma em direção à borda do casquete, criando espaço adequado para o reembasamento com resina acrílica Duralay. Verificar a adaptação do casquete no dente preparado (Figura 2). 

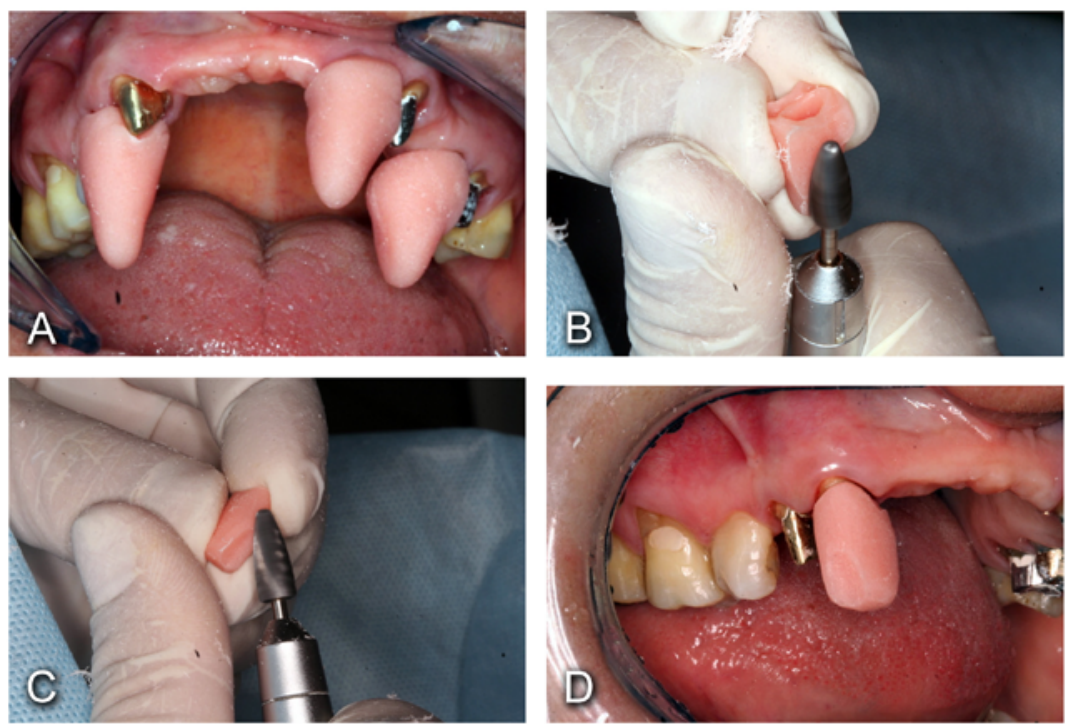

Figura 1. (A) Confecção inicial do casquete, (B) Desgaste externo do casquete, no longo eixo, (C) Marcação da superfície vestibular do casquete (D) Adaptação inicial do casquete no dente preparado.
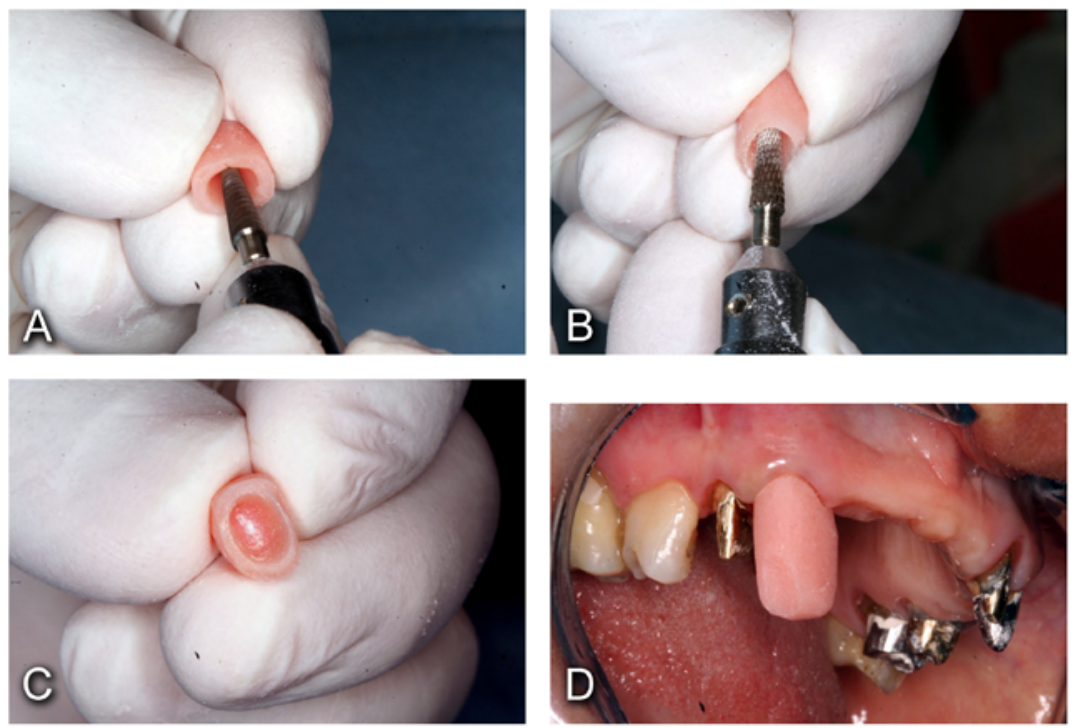

Figura 2. (A) Alívio interno do fundo do casquete, (B) Alívio das paredes laterais internas, (C) Aspecto interno do casquete após alívio interno, (D) Adaptação do casquete no dente preparado.

\section{Manipulação da resina duralay e apresentação da variação no reembasamento do casquete}

A resina deve ser manipulada com quantidade de monômero suficiente para obtenção de adequado molhamento dos grânulos e uma mistura com consistência uniforme. No início da fase fibrosa, com a superfície ainda brilhante, é levada ao interior do casquete, além das suas bordas. Em seguida, após breve inserção e remoção do conjunto casquete/resina em água, manipula-se a resina inserida no casquete até a fase plástica quando não há desprendimento de fibrilas de resina, prepara-se a resina no casquete (Figura 3 ) quando então o conjunto é le- vado ao dente preparado. A inserção do casquete é realizada em várias etapas, com compressão dos excessos contra o sulco gengival: a primeira etapa vai até o terço médio do dente preparado em trajetória retilínea seguindo o longo eixo, os excessos de resina são manualmente comprimidos na direção do sulco gengival e nas faces proximais com o auxílio de espátula 7, na segunda etapa, faz-se uma outra compressão associada a movimentos rotacionais, para que o casquete se adapte ao preparo (Figura 4). Aguardar a fase borrachóide da resina acrílica, remover do dente e imergir o conjunto em água fria. Observar se houve a penetração da resina no sulco gengival verificada pela presença de resina além 
da margem do preparo, na forma de borda afilada. No entanto, se a borda estiver arredondada, o molde estará inadequado.

Ao realizar esse procedimento deve-se ter o cuidado de remover o tecido gengival sobre as bordas do preparo que impedem a ação do casquete.
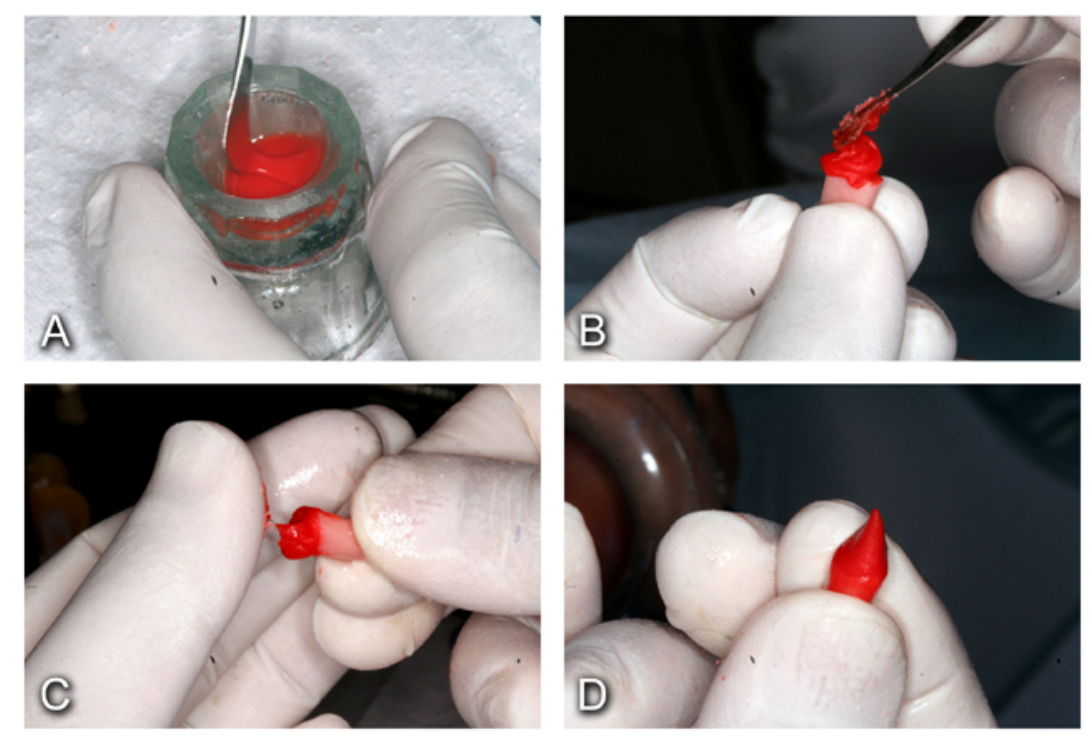

Figura 3. (A) Manipulação da resina duralay, (B) Inserção da resina duraly no interior do casquete, (C) Verificação manual da fase plástica da resina, (D) Casquete com resina duralay pronta para o reembasamento.
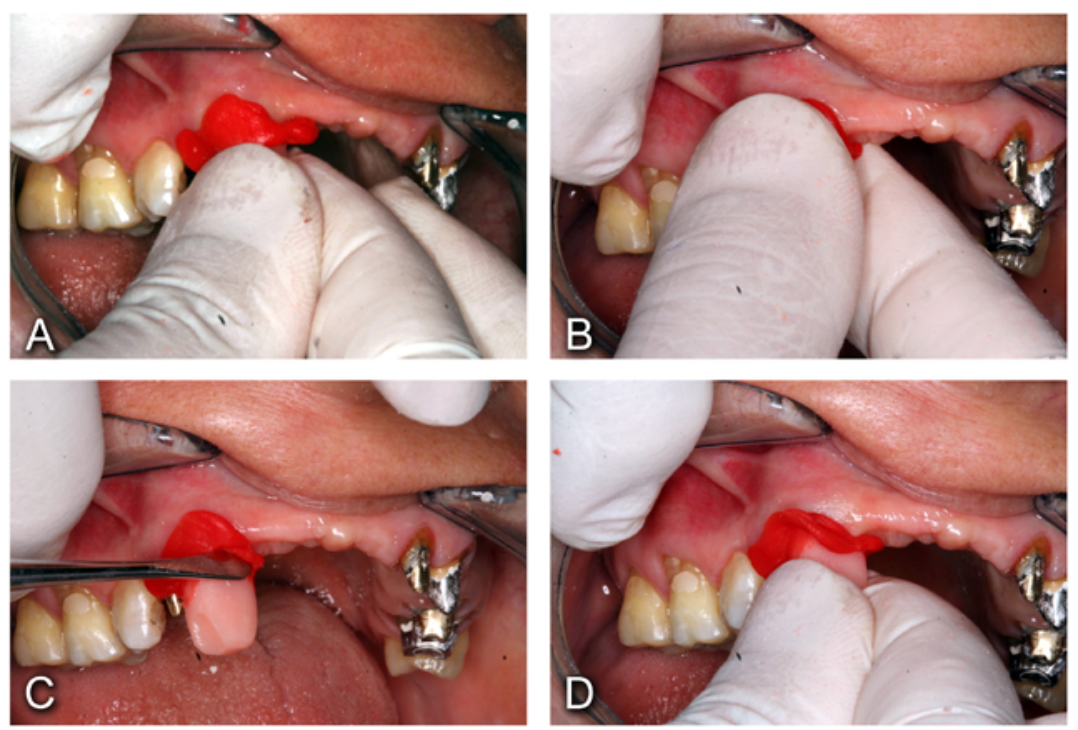

Figura 4. (A) Inserção inicial do conjunto casquete/resina duralay no dente preparado, (B) Adaptação manual da resina duralay, na região do término do preparo, (C) Adaptação com instrumento da resina duralay, nas faces proximais, (D) Inserção final com movimento rotacional. 


\section{Desgaste do casquete}

Posicionar a fresa de tungstênio na superfície externa do casquete, seguindo o longo eixo do preparo, desgastando os excessos ao nível da borda afilada (Figura 5).
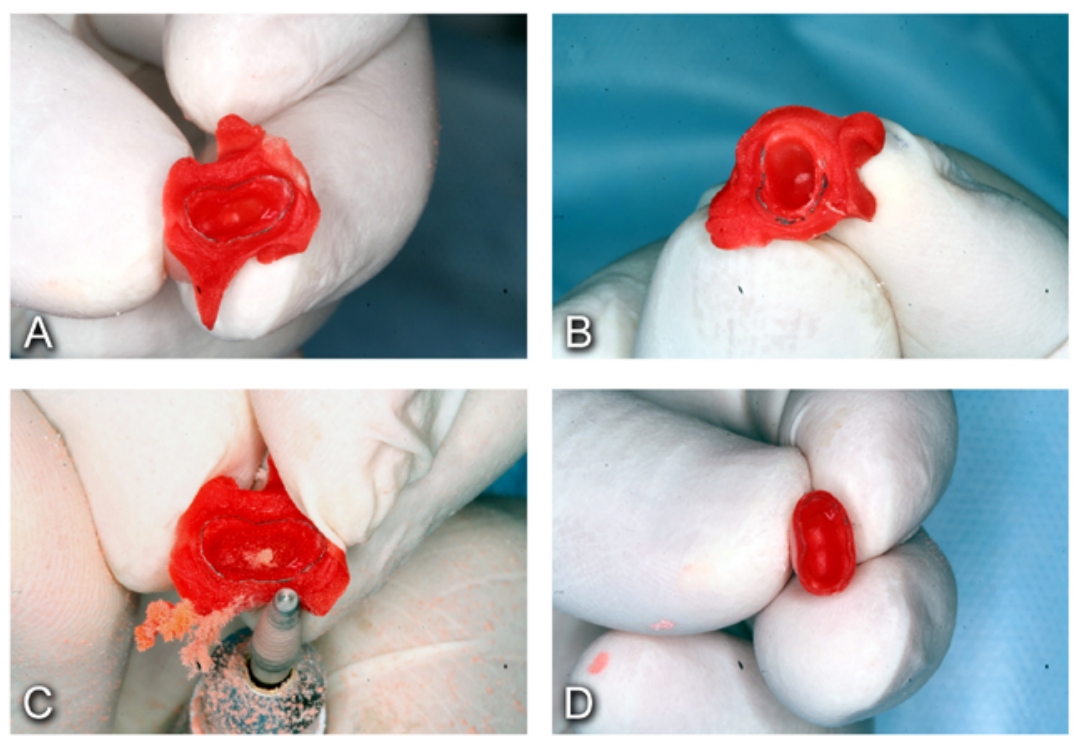

Figura 5. (A) Aspecto de casquete reembasado mostrando a continuidade do término do preparo, (B) Aspecto de casquete reembasado mostrando descontinuidade do término do preparo, (C) Desgaste externo dos excessos de resina duralay, (D) Aspecto das bordas externas do casquete após desgaste dos excessos.

Realizar o alívio interno com broca de aço esférica números 6 ou 8: O diâmetro da broca na porção oclusal ou incisal do casquete e nas paredes laterais ou axiais deve ser $1 / 2$ do diâmetro, sem interferir na borda afilada. Verificar o aspecto interno final do casquete com espaço adequado para o material de moldagem (Figura 6 ).
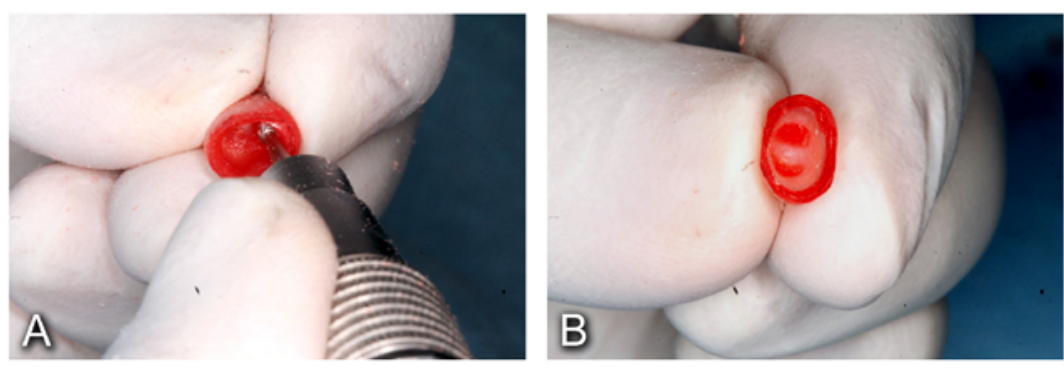

Figura 6. (A) Alívio interno do fundo do casquete e das paredes laterais, (B) Aspecto interno do casquete com espaço para o material de moldagem.

Verificar a adaptação do casquete na boca que não pode travar no dente. Caso isso ocorra, significa que há excessos na borda afilada, devendo ser removidos internamente ou no comprimento da borda.

\section{Moldagem com poliéter (Impregum - 3M ESPE)}

Passar adesivo nas bordas externas e no interior do casquete e, aguardar o secamento. Dosar as pastas base e catalisadora, proporcionalmente em comprimento, e espatular. Inserir o material de moldagem, gradativamente, para evitar inclusão de bolhas de ar no interior do casquete, até acima da borda (Figura 7). Secar a região a ser moldada. Levar o conjunto casquete/poliéter no dente preparado, retroceder e manter em posição (Figura 8). Após o tempo recomendado pelo fabricante, remover o conjunto e analisar o molde (Figura 9). 

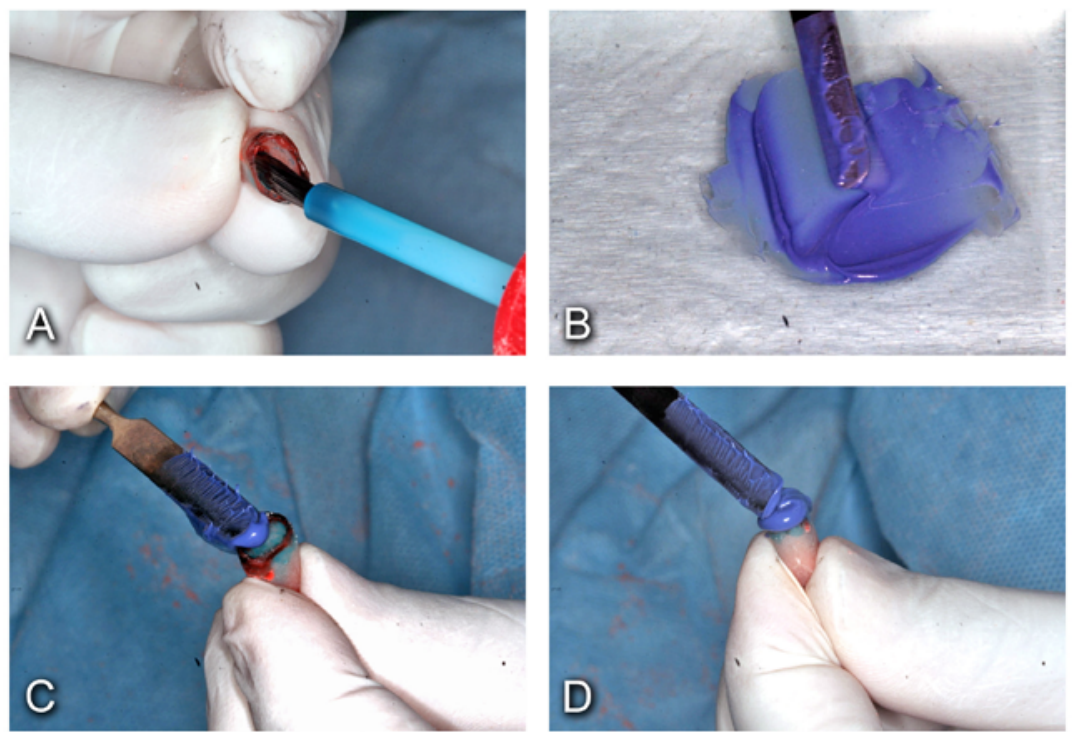

Figura 7. (A) Colocação do adesivo no interior e nas bordas externas do casquete, (B) Manipulação do material de moldagem (poliéter), (C) Início da inserção cuidadosa do material de moldagem, pela lateral do casquete para evitar bolhas de ar, (D) Preenchimento completo do interior do casquete.
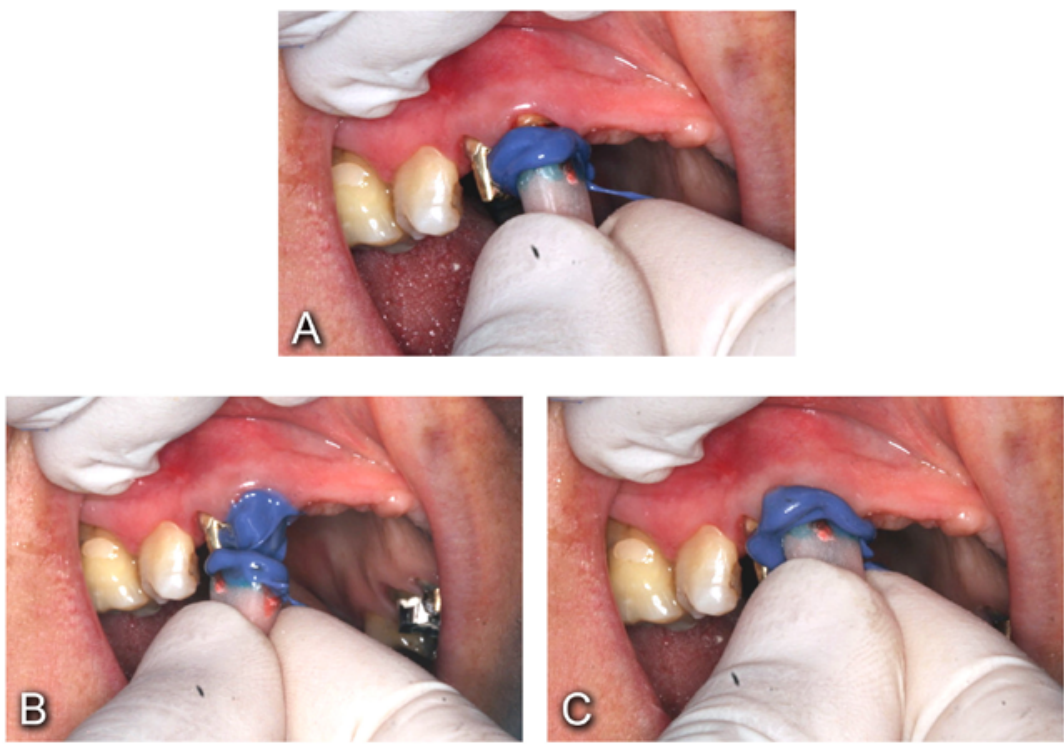

Figura 8. (A) Inserção parcial do conjunto casquete/material de moldagem sobre o dente preparado, (B) Afastamento do conjunto casquete/material de moldagem do dente preparado, (C) Inserção final e completa do conjunto casquete/material de moldagem.
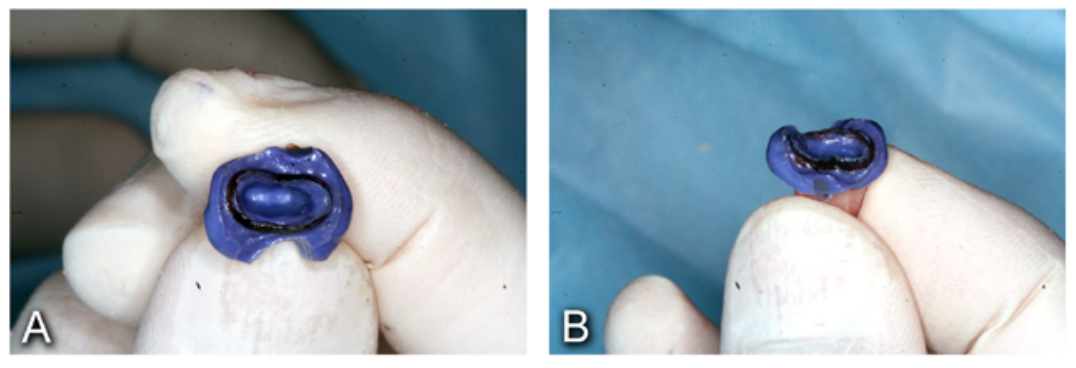

Figura 9. (A) Vista Interna do molde, (B) Vista lateral do molde. 
Plastificar parte de uma lâmina de cera 7 e envolver o casquete e o material de moldagem, formando um dique para conter o gesso tipo IV a ser vazado e assim, obter o troquel (Figura 10).

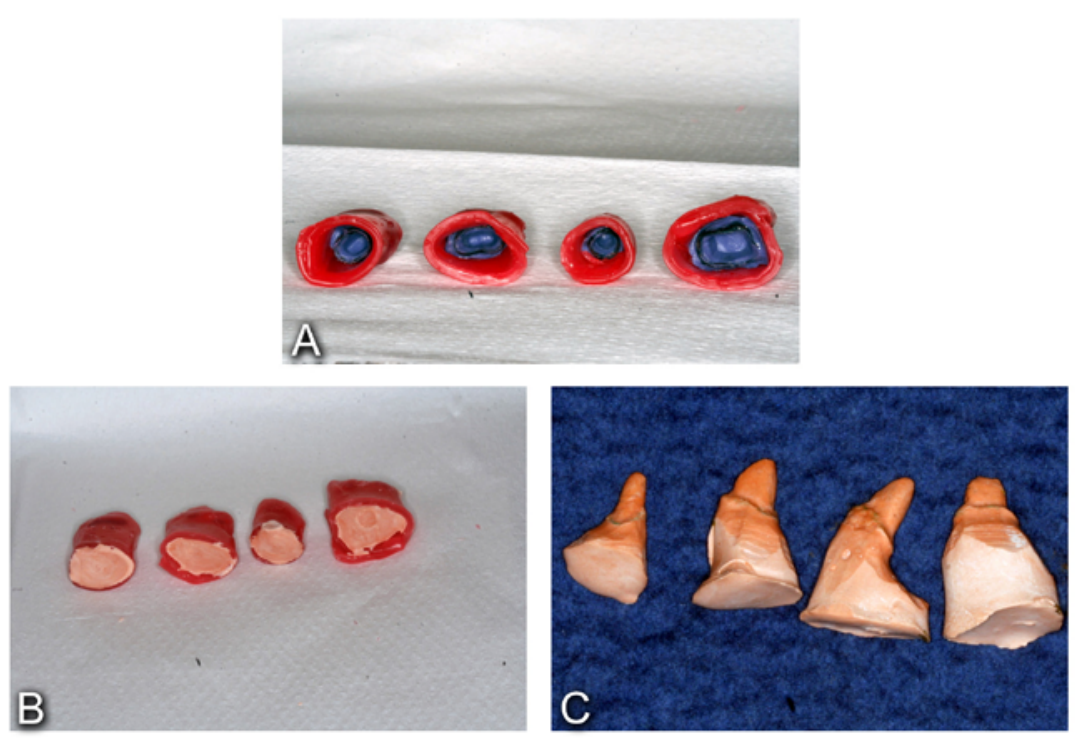

Figura 10. (A) Dicagem dos moldes com resina rosa 7, (B) Modelagem com gesso tipo IV, (C) Obtenção direta de troquéis individuais.

\section{Discussão}

A escolha pela técnica de afastamento gengival menos danosa ao periodonto deve ser considerada uma etapa importante no processo de obtenção do modelo de trabalho, tendo em vista que, a ocorrência de traumas no epitélio do sulco gengival pode induzir a retração gengival ${ }^{2}$ com potencial comprometimento estético.

Trabalhos sobre afastamento gengival, utilizando técnicas e materiais diversos, mostram suas vantagens e desvantagens ${ }^{2,5,6}$ e, a técnica do casquete é considerada eficaz e menos traumática ${ }^{7-9}$, pois a resina acrílica é levada ao elemento dental preparado numa fase em que sua consistência não promove danos aos tecidos gengivas ${ }^{2}$.

Neste trabalho, optou-se pelo detalhamento dos procedimentos realizados desde a obtenção do casquete, reembasamento, moldagem até a modelagem com o objetivo de ressaltar pequenos cuidados e variações que resultam na facilitação dos passos clínicos e laboratoriais em associação com resultados precisos.
A opção pela confecção inicial do casquete diretamente na boca, sobre o dente preparado, deu-se pela possibilidade de aproveitamento do tempo de trabalho do profissional por ser um passo simples e rápido, passível de ser executado nos intervalos de espera, como por exemplo, da polimerização extra bucal da resina adicionada à restauração provisória na fase de reembasamento. Além disso, apresenta vantagens sobre as duas outras técnicas como não necessitar de modelo de gesso e possibilitar, de imediato, tamanho de casquete adequado e não limitado ao da coroa provisória.

O desgaste interno, com broca esférica números 6 ou 8 , na oclusal (diâmetro da broca) e nas paredes laterais ( $1 / 2$ diâmetro) do casquete cria um espaço homogêo para o material de moldagem considerando que há necessidade de uma quantidade de material ( 2 a $3 \mathrm{~mm}$ ) que seja suficiente para manter suas propriedades e volume para pressionar os tecidos moles e penetrar no sulco gengival. $O$ excesso de alívio, além de não permitir pressão no interior do sulco, pode dificultar a manutenção do casquete em posição durante a moldagem e também, possibilitar quantidades diferentes de material de moldagem no interior do casquete interferindo na precisão do troquel. 
O reembasamento por adição de resina Duralay pela técnica do pincel utiliza resina em diferentes fases de polimerização e em diferentes consistências podendo interferir na decisão do momento ideal de se levar à boca, além de dificultar o afastamento gengival. Também deve ser observado que a adição de resina, por esta técnica, propicia quantidades diferentes de monômero livre que podem agredir os tecidos moles ${ }^{10,11}$ e $\circ$ dente, $\circ$ que não ocorre na presente técnica visto que tem-se o cuidado de manipular uma única porção de resina Duralay, inserir no interior do casquete, aguardar a fase em que não há mais desprendimento de fibrilas e só então levar ao dente preparado.

Quando se utiliza esta variação de técnica, a quantidade e a fase plástica da resina Duraly colocada no interior do casquete permitem volume e consistência para afastamento gengival, com menor agressão ao tecido gengival pela menor quantidade de monômero residual livre, segurança para determinar o momento de inserção do conjunto casquete-resina no dente preparado, compressão manual da resina excedente no término cervical e reembasamento diferenciado pela homogeneidade proporcionada pela inserção da resina em fase de polimerização única.

Outro fator incorporado à técnica é a utilização de troquel isolado associado a um modelo de relacionamento total, sem a utilização de modelo troquelizado que é mais difícil de confeccionar porque a moldagem por arrasto dos casquetes não possibilita a verificação da precisão do molde, o retorno do casquete moldado para o molde pode provocar alteração, a adaptação do troquel no modelo nem sempre é preciso devido aos cortes realizados com serra.

Tanto no modelo troquelizado quanto no troquel isolado, o técnico confecciona a prótese por partes, ou seja, não em monobloco (peça única), o que seria desejável. A confecção por partes exige uma sessão para ponto de solda unindo as partes, porém, como a obtenção do modelo troquelizado é mais complexa (utilização de pino para troquel, paralelismo na colocação, fixação dos pinos, etc) a técnica do troquel isolado é uma boa opção, além de permitir que as moldagens possam ser realizadas em diferentes sessões de atendimento, o que não ocorre na técnica do modelo troquelizado.

\section{Conclusão}

A variação na técnica facilita os procedimentos de reembasamento do casquete pela utilização de resina em fase homogênea e com consistência adequada para afastamento gengival; além disso, a remoção isolada do conjunto casquete e material de moldagem permite a obtenção direta do troquel de gesso.

\section{Conflitos de interesses}

Nenhum conflito financeiro, legal ou político envolvendo terceiros (governo, empresas e fundações privadas, etc.) foi declarado para nenhum aspecto do trabalho submetido (incluindo mas não limitando-se a subvenções e financiamentos, conselho consultivo, desenho de estudo, preparação de manuscrito, análise estatística, etc).

\section{Referências}

1. de Sá ATG, de Freitas CA, de Sá FC, Ursi WJS, Simões TC, de Freitas MFA. Effect of cervical relining of acrylic resin copings on the accuracy of stone dies obtained using a polyether impression material. J Appl Oral Sci. 2008; 16(1):711.

2. Ribeiro JGR, Costa AMM, Junqueira Neto JFA, Segalla $J C M$, Perez F. Alternative technique for gingival displacement and impression with individual custom tray. Rev Odontol UNESP. 2005; 34(4):179-183.

3. Alves MC, Soares CR, Zani IM. Estabilidade dimensional dos moldes de poliéter e polissulfeto obtidos com a técnica do casquete de acrílico, vazados em gesso pedra especial tipo IV e V. Revista Odonto Ciência. 2005; 20(48): 120-125.

4. Pegoraro LF, Valle AL, Araújo CRP, Bonfante G, Conti PCR, Bonachela V. Prótese Fixa. São Paulo: Artes Médicas: EAPAPCD, 2004. (Série EAP-APCD; Vol.7)

5. Hoffman JM. Nontraumatic final impressions for fixed partial dentures. J Prosthodont. 1992;1(1):61-64.

6. Nishioka RS, Duarte CA, Carvalho YR, Nakae K, Bottino $M A$. Afastamento gengival: estudo histológico comparativo em cães, entre a eletrocirurgia e o uso do fio de algodão embebido em cloreto de zinco e em cloreto de alumínio. Rev Odontol UNESP. 1999;28(2):239-250. 
7. Cannistraci GJ. A new approach to impression taking for crown and bridge. Dent Clin North Am. 1965;29:33-42.

8. Dimashkieh MR, Morgano SM. A procedure for making fixed prosthodontics impressions with the use of preformed crown shells. J Prosthet Dent. 1995;73(1):95-6.

9. Spyrides GM, Spyrides SMM, Ferreira ABC, Ferreira EC. Moldagem com casquete de resina/elastômero: método alternativo e simplificado para obtenção do casquete acrílico. Rev Bras Odontol. 1998;55(3):160-164.

10. Stungis TE, Fink JN. Hypersensitivity to acrylic resin. J Prosthet Dent. 1969;22(4):425-428.

11. Hochman N, Zalkind M. Hypersensitivity to methyl methacrylate: mode of treatment. J Prosthet Dent.

$1997 ; 77(1): 93-96$. 